\title{
a-Fetoprotein (AFP)-L3\% and transforming growth factor B1 (TGFB1) in prognosis of hepatocellular carcinoma after radiofrequency
}

\author{
Ahmed Shawky Elsawabi ${ }^{1}$, Khaled Abdel wahab', Wesam Ibrahim', Shereen Saleh ${ }^{1 *}$ (D, Yasmine Massoud ${ }^{2}$, \\ Mohamed Abdelbary ${ }^{3}$ and Ahmed Nabih $^{4}$
}

\begin{abstract}
Background: Numerous hepatocellular carcinoma (HCC) biomarkers have been assessed in the diagnosis and prognosis of HCC. The aim of this study was to assess the value of a-fetoprotein (AFP)-L3\% and transforming growth factor B1 (TGFB1) as prognostic markers in hepatocellular carcinoma after radiofrequency ablation (RFA). This observational cohort study included 40 patients with HCC diagnosed by triphasic computed tomography criteria indicated for radiofrequency ablation. Serum AFP, AFP-L3\%, and TGFB1 were measured in all patients before and 3 months after radiofrequency ablation.

Results: Statistically significant lower levels of TGFB1, AFP, and AFP-L3\% were noted in the HCC patients after radiofrequency ablation. Significant lower levels of TGFB1, AFP, and AFP-L3\% were found in the no recurrence group in comparison to the recurrence group. The cutoff value of TGFB1 $>56.87 \mathrm{ng} / \mathrm{mL}$, AFP $>74.9 \mathrm{ng} / \mathrm{mL}$, and AFP-L3\% > 8.5\% was the best in the discrimination of tumor recurrence with sensitivity of $85.7 \%, 57.1 \%$, and $100 \%$; specificity of $54.6 \%, 84.9 \%$, and $100 \%$; and diagnostic accuracy of $64.5 \%, 69 \%$, and $100 \%$, respectively.

Conclusion: TGFB1 and AFP-L3\% are good prognostic markers for HCC. They could be used to monitor the response of HCC to treatment.
\end{abstract}

Keywords: Hepatocellular carcinoma (HCC), a-Fetoprotein (AFP), AFP-L3\%, Transforming growth factor B1 (TGFB1)

\section{Background}

Hepatocellular carcinoma (HCC) is the fifth common cancer worldwide and the third most common cause of cancer-related death [1]. Egypt is considered as one of the hot spots on the map of HCC as hepatitis $\mathrm{C}$ virus $(\mathrm{HCV})$ infection is the major risk factor in the development of HCC [2].

Despite its limitations, $\alpha$-fetoprotein (AFP) remains the most widely used HCC biomarker. Recent studies should focus on combining biomarkers to achieve maximum diagnostic and predictive value [3].

\footnotetext{
* Correspondence: shereen_saleh2014@hotmail.com

1 Department of Internal Medicine, Gastroenterology and Hepatology Unit,

Faculty of Medicine, Ain Shams University, Cairo 11566, Egypt

Full list of author information is available at the end of the article
}

AFP is glycosylated in several hepatic diseases. Uridine diphosphate (UDP)-alpha-(1,6)-fucosyl transferase is differentially expressed in hepatocytes as a result of malignant transformation [4]. The enzyme contains fucose residues on the carbohydrate chains of AFP. Different glycosylated forms of AFP can be found following electrophoresis by reaction with different carbohydratebinding plant lectins. The fucosylated form of AFP which relates to hepatocellular carcinoma is recognized by a lectin from the common lentil (Lens culinaris). It is known as AFP-L3. AFP-L3 is useful in the diagnosis of HCC from benign conditions as chronic liver diseases where AFP-L1 is the non-Lens culinaris agglutinin (LCA)-bound fraction constitutes most of the glycoform of AFP in chronic liver disease and cirrhotic liver especially if AFP is $\leq 200 \mathrm{ng} / \mathrm{mL}$ [4]. 
AFP-L3 is produced by malignant hepatocytes, even if $\mathrm{HCC}$ is at its early stages [5]. It is associated with aggressive HCCs [6]. It could predict HCC in patients with chronic hepatitis especially if associated with other HCC biomarkers [7]. Besides, AFP-L3\% is great in detecting recurrent $\mathrm{HCC}$ following treatment [6].

Levels of AFP-L3 $\geq 10 \%$ are most probably associated with underlying HCC. In patients with total AFP level $\leq$ $200 \mathrm{ng} / \mathrm{mL}$, AFP-L3 specificity may reach $100 \%$ for hepatocellular carcinoma if it increases more than $35 \%$ of the total AFP [6].

TGFB1 is a multifunctional cytokine regulating growth, migration, differentiation, and apoptosis of different epithelial and hematopoietic cells. It is a part of a superfamily of proteins known as the TGFB superfamily; there are three isoforms called TGFB1, TGFB2, and TGFB3 [8]. TGFB1 messenger-ribonucleic acid (mRNA) and its protein were overexpressed in HCC compared with the other liver tissues, especially in small-sized and well-differentiated HCCs [9]. In HCC, TGF $\beta 1$ is quiet a useful serologic marker for diagnosis because of its higher sensitivity than AFP in earlier stage of cancer [9].

The purpose of this study was to assess the effectiveness of AFP-L3\% and TGFB1 as prognostic markers of hepatocellular carcinoma after radiofrequency ablation.

\section{Methods}

This observational cohort study was carried out at Ain Shams and Helwan Universities and Luxor International Hospitals. The patients were recruited from the radiology unit and the in-patients of internal medicine (gastroenterology and hepatology unit) departments and outpatient clinic during the period from May 2016 till May 2017 after approval from the Research and Ethics Committee of Ain Shams University in accordance with the local research governance requirements. This study was performed in accordance with the 1964 Declaration of Helsinki and all subsequent revisions.

The study included 40 patients with HCC on top of hepatitis C liver cirrhosis. HCC was diagnosed by imaging characteristics of computed tomography criteria (arterial hypervascularity and porto-venous or delayed washout), based on the American Association for the Study of Liver Diseases (AASLD) practice guidelines 2010 on the management of hepatocellular carcinoma (HCC) [10], and indicated for radiofrequency ablation (RFA). RFA was performed according to the protocol of the radiology departments in Ain Shams and Helwan Universities and Luxor International Hospitals and following Barcelona Clinic Liver Cancer (BCLC) guidelines for the management of HCC [11].

Exclusion criteria are patients with bile duct or major vessel invasion, lesions that are difficult to reach with electrodes or when electrode placement is impaired, large or numerous tumors more than 5 or each of them more than $3 \mathrm{~cm}$, Child $\mathrm{C}$ cirrhotic patients, patients with active infection, patients with metastatic lesions, and patients with significant extrahepatic disease.

All patients in this study were subjected to the following:

1. Detailed history taking with complete physical examination.

2. Complete blood count using Coulter counter (T660).

3. ESR: Estimation was done by the Westergren method recorded in millimeters/hour.

4. Routine random blood sugar, urea, and creatinine and full liver work up: [serum glutamic pyruvic transaminase (SGPT), serum glutamic-oxaloacetic transaminase (SGOT), total and direct bilirubin, alkaline phosphatase, gamma-glutamyl transferase (GGT), and serum albumin] using fully automated chemistry analyzer.

5. Prothrombin time using fully coagulation analyzer.

6. Virology screening for hepatitis $\mathrm{C}$ virus (HCV) $\mathrm{Ab}$ and hepatitis B surface antigen (HBsAg) by third-generation ELISA.

7. The model for end-stage liver disease (MELD) score and Child-Pugh score were calculated for the included patients.

8. Total serum AFP and AFP-L3\% were measured using specific human enzyme-linked immunosorbent assay (ELISA) kit designed for the quantitative measurement of AFP in the serum (Green STONE Swiss CO, Shanghai, China). Assay range is $50-1600$ $\mathrm{ng} / \mathrm{mL}$. Reference range of AFPL3 is 0.5-9.9\%.

9. Serum TGFB1 was measured using TGFB1 ELISA kit (Green STONE Swiss CO, Shanghai, China). Assay range is $40-1000 \mathrm{ng} / \mathrm{mL}$. Serum alphafetoprotein L3 (AFP-L3) and transforming growth factor B1 (TGFB1) were measured to all patients before and 3 months after radiofrequency ablation.

10. Imaging studies: All patients were subjected to detailed abdominal ultrasonography and triphasic computerized tomography (CT) examinations with a comment on liver size, echogenicity, focal lesion (size, site, and number), enhancement criteria, spleen size, portal vein diameter, and ascites.

11. Assessment and follow-up: The response to RFA was assessed by contrast enhanced-triphasic $\mathrm{CT}$ after 4 weeks of RFA according to the modified Response Evaluation Criteria in Solid Tumors (mRECIST) [11]. The patients were re-evaluated after 3 months by triphasic CT, AFP, AFP-L3, and TGFB1.

Complete ablation was characterized by the development of a non-enhancing area, including the tumor and the ablative margin $(0.5-1 \mathrm{~cm})$, throughout all phases of 
the triphasic CT done 4 weeks after the RFA. Incomplete ablation is defined by the presence of residual focal or marginal area of enhancement at the arterial phase with washout at the porto-venous or delayed phase, in the follow-up triphasic CT done after 4 weeks of RFA. Recurrence was characterized by the development of de novo lesions occurring at a distance exceeding $1 \mathrm{~cm}$ from the original lesion, the development of a new lesion in separate liver segments, or the development of new lesions that appeared within the follow-up period at the ablative margin or the track of a previously well-ablated tumor $[12,13]$.

\section{Statistical analysis}

Data were collected, revised, coded, and analyzed using Statistical Program for Social Science (SPSS) version 20.0 (IBMథ Corp., Armonk, NY, USA). Quantitative data were expressed as mean \pm standard deviation (SD). Qualitative data were expressed as number and percentage. Independent sample $t$ test of significance was used when comparing between two means. Paired sample $t$ test of significance was used when comparing between related samples. Chi-square $\left(\chi^{2}\right)$ test of significance was used to compare proportions between two qualitative parameters. Pearson's correlation coefficient $(r)$ test was used for correlating data. The sensitivity, specificity, and positive and negative predictive values were determined for several cutoff values, and a receiver operating characteristic (ROC) curve was constructed. Probability ( $p$ value) $<0.05$ was considered significant and $p$ value $>$ 0.05 was considered insignificant.

\section{Results}

This study included 40 patients with HCC on top of hepatitis $C$ liver cirrhosis. The mean age of the patients was $63.8 \pm 6.57$. Thirty-two $(80 \%)$ of the patient group were males, and eight (20\%) were females. The patients' MELD score mean was $3.98 \pm 7.59$ with a range of $13-$ 19. All of them had Child A liver cirrhosis on top of $\mathrm{HCV}$. In the HCC group, tumor size ranged from 3 to $50 \mathrm{~mm}$. Seven (17.5\%) of HCC patients showed tumor recurrence.
Statistically significant lower levels of TGFB1, AFP, and AFP-L3\% were noted after radiofrequency ablation in comparison to the pre-RFA levels in the HCC patients (Table 1). Also, significant higher post-RFA levels of TGFB1, AFP, and AFP-L3\% were found in patients with HCC recurrence in comparison with those with no recurrence (Table 2). There was statistically significant correlation between AFP-L3\% and tumor recurrence in the patient group after RFA (Table 3). There were significant correlations between TGFB1 and total bilirubin, INR, serum albumin, ALKP, MELD score, Child class, and platelets (Table 4).

ROC curve was used to assess the diagnostic performance after radiofrequency ablation in the prediction of tumor recurrence. Cutoff values of TGFB1 $>56.87 \mathrm{ng} /$ $\mathrm{mL}, \mathrm{AFP}>74.9 \mathrm{ng} / \mathrm{mL}$, and AFP-L3\% $>8.5$ were the best in the prediction of tumor recurrence. These cutoffs showed high sensitivity but low specificity for TGFB1, high specificity but low sensitivity for AFP, and both high sensitivity and specificity for AFP-L3\% (Table 5, Fig. 1).

\section{Discussion}

Thirty-two $(80 \%)$ of the patients in the current study were males and eight (20\%) patients were females; their ages ranged from 50 to 80 years. These findings agreed with Holah and colleagues, in which the clinical and demographic data revealed that $51.1 \%$ of their studied HCC patients were at least 58 years old, $81.5 \%$ were males and $18.5 \%$ were females [14]. Similarly, El-Zayadi and colleagues studied the prevalence and epidemiological features of HCC in Egypt and found out that out of 321 HCC patients, $82.55 \%$ were males, and $17.45 \%$ were females. The precise reason is not so clear, but it has been shown that many tumors have androgen receptors, and there is also a male predominance in the HCC risk factors [15].

In the current study, the tumor size ranged from 3 $\mathrm{mm}$ to $50 \mathrm{~mm}$. All patients had $\mathrm{HCC}$ lesion $<3 \mathrm{~cm}$ in size except for one patient who had a lesion reaching up to $5 \mathrm{~cm}$. According to the BCLC guidelines, tumors exceeding $3 \mathrm{~cm}$ in diameter are better to be handled by combination therapy with arterially directed modality

Table 1 TGFB1, AFP, and AFP-L\% before and after radiofrequency in patients' group

\begin{tabular}{|c|c|c|c|c|}
\hline & Before RFA & After RFA & Statistical test & $p$ value \\
\hline TGFB1 ng/mL (mean \pm SD) & $63.22 \pm 23.61$ & $56.53 \pm 24.34$ & $2.65^{\wedge}$ & 0.01 \\
\hline AFP ng/mL (mean \pm SD) & $85.33 \pm 61.62$ & $47.10 \pm 32.17$ & $6.35^{\wedge}$ & $<0.001$ \\
\hline AFP-L3\% (mean \pm SD) & $28.55 \pm 13.13$ & $10.58 \pm 9.82$ & $5.42^{\wedge}$ & $<0.001$ \\
\hline AFP-L3\% < $10 \mathrm{~N}(\%)$ & $1(2.5 \%)$ & 33 (82.5\%) & $49.15^{\#}$ & $<0.001$ \\
\hline AFP-L3\% > $10 \mathrm{~N}(\%)$ & $39(97.5 \%)$ & $7(17.5 \%)$ & & \\
\hline
\end{tabular}

$N$ number

${ }^{\wedge}$ Paired $t$ test

\#Chi-square test 
Table 2 Comparison between the tumor recurrence group and group with no tumor recurrence regarding pre- and postradiofrequency TGFB1, AFP, and AFP-L3\%

\begin{tabular}{|c|c|c|c|c|}
\hline & \multicolumn{2}{|c|}{ Tumor recurrence } & \multicolumn{2}{|l|}{$t$ test } \\
\hline & \multirow{2}{*}{$\begin{array}{l}\text { Yes } \\
\text { Mean } \pm \text { SD }\end{array}$} & \multirow{2}{*}{$\begin{array}{l}\text { No } \\
\text { Mean } \pm \text { SD }\end{array}$} & & \\
\hline & & & $t$ & $p$ value \\
\hline Pre-TGFB1 (ng/mL) & $62.70 \pm 24.75$ & $63.33 \pm 23.76$ & -0.064 & 0.950 \\
\hline Post-TGFB1 (ng/mL) & $66.72 \pm 16.08$ & $54.37 \pm 25.42$ & 1.227 & 0.228 \\
\hline$p$ value & 0.461 & $<0.001$ & & \\
\hline Pre-AFP (ng/mL) & $91.97 \pm 63.07$ & $83.92 \pm 62.21$ & 0.310 & 0.758 \\
\hline Post-AFP (ng/mL) & $66.91 \pm 36.37$ & $42.89 \pm 30.16$ & 1.849 & 0.072 \\
\hline$p$ value & 0.093 & $<0.001$ & & \\
\hline Pre-AFP-L3\% & $35.53 \pm 15.68$ & $27.07 \pm 12.29$ & 1.577 & 0.123 \\
\hline Post-AFP-L3\% & $53.10 \pm 15.03$ & $1.56 \pm 2.53$ & 19.322 & $<0.001$ \\
\hline$p$ value & 0.036 & $<0.001$ & & \\
\hline
\end{tabular}

and RFA. Yet for economic reasons, we could not perform transcatheter arterial chemoembolization (TACE) following RFA for our patient, but instead, we used cluster cool-tip electrode from Covidien. We tried to achieve an ablative margin of at least $1 \mathrm{~cm}$ in all cases. As previously discussed in several studies and as previously reported by Ke et al., lesions from 3 to $5 \mathrm{~cm}$ could be ablated with a low recurrence rate if the ablative margin is at least $1 \mathrm{~cm}$ [16].

The recurrence rate of the tumor after 3 months of the local treatment in the current study was $17.5 \%$. This somehow agrees with Wang et al., who found that $16.6 \%$

Table 3 Correlation between AFP-L3\% and other parameters using Pearson's correlation coefficient in the patients' group

\begin{tabular}{|c|c|c|c|c|}
\hline & \multicolumn{4}{|l|}{ AFPL3\% } \\
\hline & \multicolumn{2}{|l|}{ Pre-RFA } & \multicolumn{2}{|c|}{ Post-RFA } \\
\hline & $r$ & $p$ value & $r$ & $p$ value \\
\hline Age (years) & 0.077 & 0.637 & -0.209 & 0.196 \\
\hline INR & 0.147 & 0.365 & -0.037 & 0.820 \\
\hline Total bilirubin & 0.147 & 0.366 & -0.024 & 0.885 \\
\hline Albumin & -0.242 & 0.133 & -0.117 & 0.472 \\
\hline ALT & 0.062 & 0.705 & 0.159 & 0.328 \\
\hline AST & -0.093 & 0.569 & 0.121 & 0.455 \\
\hline Tumor size by millimeters & 0.145 & 0.371 & -0.263 & 0.101 \\
\hline Tumor recurrence & 0.248 & 0.123 & .953 & $<0.001$ \\
\hline Alkaline phosphatase & -0.165 & 0.308 & 0.238 & 0.139 \\
\hline Urea & 0.160 & 0.326 & 0.168 & 0.299 \\
\hline Creatinine & 0.286 & 0.074 & 0.114 & 0.484 \\
\hline Ascites & -0.137 & 0.401 & -0.121 & 0.458 \\
\hline MELD & 0.286 & 0.073 & 0.062 & 0.705 \\
\hline Child-Pugh class & 0.033 & 0.839 & -0.037 & 0.819 \\
\hline Platelet count & -0.015 & 0.925 & -0.099 & 0.544 \\
\hline
\end{tabular}

Table 4 Correlation between TGFB1 and other parameters using Pearson's correlation coefficient in the patients' group

\begin{tabular}{|c|c|c|c|c|}
\hline & \multicolumn{2}{|c|}{ Pre-TGFB1 } & \multicolumn{2}{|c|}{ Post-TGFB1 } \\
\hline & $r$ & $p$ value & $r$ & $p$ value \\
\hline Age (years) & 0.046 & 0.779 & -0.159 & 0.327 \\
\hline INR & -0.374 & 0.018 & -0.555 & $<0.001$ \\
\hline Total bilirubin & -0.594 & $<0.001$ & -0.699 & $<0.001$ \\
\hline Albumin & 0.598 & $<0.001$ & 0.520 & $<0.001$ \\
\hline ALT & 0.113 & 0.489 & 0.012 & 0.940 \\
\hline AST & 0.029 & 0.861 & 0.018 & 0.913 \\
\hline Tumor size by millimeters & 0.011 & 0.947 & 0.070 & 0.667 \\
\hline Tumor recurrence & -0.010 & 0.950 & 0.195 & 0.228 \\
\hline Alkaline phosphatase & 0.397 & 0.011 & 0.353 & 0.025 \\
\hline Urea & -0.105 & 0.520 & -0.079 & 0.627 \\
\hline Creatinine & 0.081 & 0.619 & 0.086 & 0.597 \\
\hline Ascites & 0.052 & 0.748 & -0.037 & 0.822 \\
\hline MELD & -0.412 & 0.008 & -0.518 & $<0.001$ \\
\hline Child-Pugh class & -0.612 & $<0.001$ & -0.616 & $<0.001$ \\
\hline Platelet count & 0.426 & 0.006 & 0.496 & $<0.001$ \\
\hline
\end{tabular}

of their radiofrequency-treated patients experienced a relapse within 6 months [17]. On the other hand, this disagrees with Toshimori et al., who found that local recurrence after RFA was $2.2 \%$ within the first year of follow-up [18]. The risk factors for tumor recurrence after RFA included tumor size, the insufficient safety margin, multinodular tumor, and tumor location [19]. Among these risk factors, tumor size $>2.3-3.0 \mathrm{~cm}$ is the main risk factor for local recurrence. Moreover, mechanical or thermal damage during RFA has been proposed to be one of the causes of recurrence, especially the more aggressive forms [20].

This study showed significant decrease in AFP and AFPL3\% levels after RF ablation. Also, there was a statistically significant reduction in serum AFP level and in AFP-L3\% after RFA in patients without tumor recurrence in contrast to those who had tumor recurrence. Zhang et al. detected a reduction in serum AFP and AFP-L3\% levels after hepatectomy for HCC; in those without tumor recurrence, on the contrary, this was not the case in non-responding patients with tumor recurrence in whom AFP-L3/AFP\% remained high. The failure of AFP-L3\% reduction or its further

Table 5 Diagnostic performance of TGFB1, AFP, and AFP-L3\% after radiofrequency ablation in the prediction of tumor recurrence

\begin{tabular}{lllllll}
\hline Items & Cutoff & Sens. & Spec. & PPV & NPV & Accuracy \\
\hline TGFB1 & $>56.87 \mathrm{ng} / \mathrm{mL}$ & $85.7 \%$ & $54.6 \%$ & $28.6 \%$ & $94.7 \%$ & $64.5 \%$ \\
AFP & $>74.9 \mathrm{ng} / \mathrm{mL}$ & $57.1 \%$ & $84.9 \%$ & $44.4 \%$ & $90.3 \%$ & $69.0 \%$ \\
AFP-L3\% & $>8.5 \%$ & $100 \%$ & $100 \%$ & $100 \%$ & $100 \%$ & $100 \%$ \\
\hline
\end{tabular}




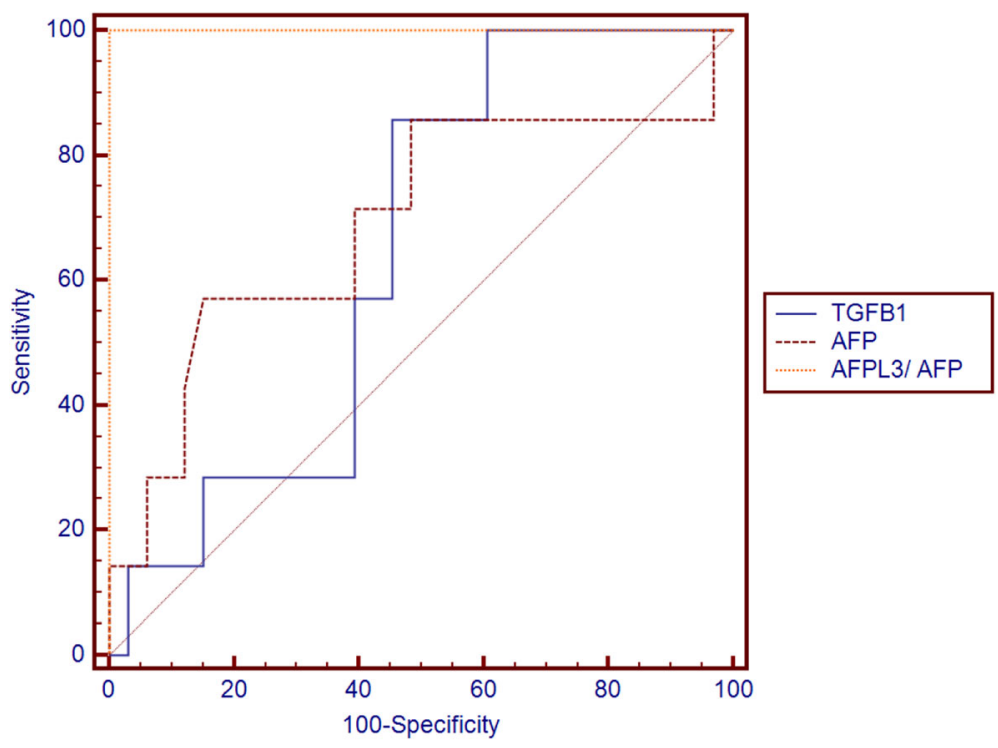

Fig. 1 Receiver operating curve (ROC) demonstrating sensitivity and specificity of TGFB1, AFP, and AFP-L3\% in prediction of tumor recurrence

elevation after $\mathrm{HCC}$ intervention was found to be a warning signal and significantly correlated with the interval of tumor recurrence and patient survival [21].

The current study showed that failure of AFP-L3/AFP\% declines from above $10 \%$ to below $10 \%$ after RFA was associated with tumor recurrence. This is consistent with Yamashita et al., who evaluated the prognostic value of AFP-L3\% in patients with liver cancer. AFP-L3\% was > 10\% in patients with evident tumor recurrence after TACE. Overall survival was significantly lower in patients with AFP-L3 > 10\%. AFP-L3\% was considered as an independent prognostic factor for liver cancer [22]. Patients with decreasing AFP-L3\% levels below 10\% after TACE showed cumulative better survival rate with significant difference compared to patients with AFP-L3\% > 10\% [22]. Similarly, Okuda et al. measured AFP-L3\% before and after surgical treatment in 130 patients with liver cancer. Postoperative AFP-L3\% > 10\% was an indicator for poorer prognosis and significant recurrence rate. AFP-L3\% was a significant independent factor for predicting survival after surgery for liver cancer [23]. In another study by Hayashi et al., AFP-L3\% was measured in patients with small liver cancer. The patients were followed using AFP-L3\% for 5 years. It was found that patients with AFP-L3 $<10 \%$ had a longer cumulative survival rate and less recurrence rate [24].

In the current study, statistically significant reduction in the mean TGFB1 levels was noted after RFA in HCC patients. It was more evident in patients without tumor recurrence. This agrees with a study by Tsai et al. which showed significantly higher TGFB1 level in HCC patients with worsening Child-Pugh stages, diffuse HCC, tumor size $>3 \mathrm{~cm}$, and multi-lobular tumor. They found that TGFB1 levels declined after complete treatment with TACE [25]. Similarly, Ji et al. reported that high TGFB1 expression was associated with tumor recurrence and worse prognosis after surgical resection of HCC [26]. Kohla et al. also found that serum levels of TGF- $\beta 1$ in HCC patients were associated with more advanced BCLC stages, larger tumors, and tumor vascular invasion [27]. These findings signified the role of TGF- $\beta 1$ in tumor growth and progression. As cancer develops, cancer cells become more resistant to the growth inhibitory properties of TGF- $\beta 1$, and both the cancer cells and the stromal cells often increase the production of TGF- $\beta 1$ which stimulates angiogenesis and cell motility. Also, it suppresses immune response with the extracellular matrix and increases the interaction of tumor cell leading to greater invasiveness and metastatic potential of the cancer [27].

Pretreatment levels of AFP and AFP-L3\% were statistically incomparable between patients with tumor recurrence and those without in the present study. This disagreed with Toro et al. who reported that extremely high pretreatment serum of AFP predicts poor outcome [28]. Corey and Pratts found an association between the mortality rate and pretreatment serum AFP level. The survival rates reached $88.9 \%$ with pretreatment AFP levels $20-250 \mu \mathrm{g} / \mathrm{L}$, and $69.6 \%$ with serum AFP level > $250 \mu \mathrm{g} / \mathrm{L}$. These results showed that HCC patients with a serum AFP level of $>250 \mu \mathrm{g} / \mathrm{L}$ had a higher mortality rate than those with a serum AFP level of $\leq 250 \mu \mathrm{g} / \mathrm{L}$ [29]. On the other hand, Wang et al. noted that AFP and AFP-L3 statuses before treatment were not related to the recurrence rate [30].

A meta-analysis was carried out to evaluate the association between high pretreatment serum AFP-L3\% and 
overall survival (OS) and disease-free survival (DFS) in HCC patients. It suggested that high pretreatment serum AFP-L3\% levels indicated a poor prognosis for patients with HCC; thus, AFP-L3\% may have significant prognostic value in HCC patients with low AFP concentration [31].

The current study showed that the cutoff value of TGFB1 $>56.87 \mathrm{ng} / \mathrm{ml}$, AFP $>74.9 \mathrm{ng} / \mathrm{ml}$, AFPL3\% > 8.5\% was the best in discrimination of tumor recurrence with sensitivity of $85.7 \%, 57.1 \%$, and $100 \%$; specificity of $54.6 \%$, $84.9 \%$, and $100 \%$; and diagnostic accuracy of $64.5 \%, 69 \%$, and $100 \%$, respectively.

\section{Conclusion}

TGFB1 and AFPL3 may serve as prognostic markers for HCC. They could be used to monitor the response of HCC to treatment.

\section{Abbreviations}

AFP: a-Fetoprotein; AFP-L3\%: a-Fetoprotein L3; CLD: Chronic liver disease; HCC: Hepatocellular carcinoma; HCV: Hepatitis C virus; RFA: Radiofrequency ablation; ROC: Receiver operating characteristic; TACE: Transcatheter arterial chemoembolization; TGFB1: Transforming growth factor B1

\section{Acknowledgements}

The authors thank all the staff members of the radiology and internal medicine (gastroenterology and hepatology unit) departments at Luxor International Hospital, Luxor, Egypt, and all the staff members of Internal Medicine and Tropical Medicine departments at Ain Shams University Hospital, Cairo, Egypt.

\begin{abstract}
Authors' contributions
Dr. AS contributed to the revision of the work and to the acceptance of the final form of the manuscript. Dr. KhA contributed in the conception and design of the work and in the revision of the manuscript. Dr. WI contributed in the revision of the manuscript and follow up of the work. Dr. SS contributed to the writing of the manuscript, revision of the work, and the publication process. Dr. YM contributed in the writing the manuscript, language polishing, and revision of the work. Dr. MH contributed in the clinical part of the work and in the revision and language polishing of the manuscript. Dr. AN contributed in the conception and the design of the work together with collection of data and in performing the statistical part of the work. All the materials and data are available. All authors have read and approved the manuscript.
\end{abstract}

\section{Funding}

This research did not receive any specific grant from funding agencies in the public, commercial, or not-for-profit sectors.

\section{Availability of data and materials \\ All data and materials are available.}

\section{Ethics approval and consent to participate}

This study was reviewed and approved by the Research Ethics Committee of the Faculty of Medicine, Ain Shams University (committee's reference number: 138/2016). Ethical approval: All procedures performed in studies involving human participants were in accordance with the ethical standards of the institutional and/or national research committee and with the 1964 Helsinki declaration and its later amendments or comparable ethical standards. Informed written consent was obtained from all individual participants included in the study.

\section{Consent for publication}

Not applicable

\section{Competing interests}

The authors declare that they have no competing interests.

\section{Author details}

'Department of Internal Medicine, Gastroenterology and Hepatology Unit, Faculty of Medicine, Ain Shams University, Cairo 11566, Egypt. ²Department of Tropical Medicine, Faculty of Medicine, Ain Shams University, Cairo, Egypt. ${ }^{3}$ Department of Interventional Radiology, Faculty of Medicine, Helwan University, Cairo, Egypt. ${ }^{4}$ Internal Medicine Department, Luxor International Hospital, Luxor, Egypt.

Received: 12 July 2019 Accepted: 30 October 2019

Published online: 18 December 2019

\section{References}

1. Ghouri YA, Mian I, Rowe JH (2017) Review of hepatocellular carcinoma: epidemiology, etiology, and carcinogenesis. J Carcinog 16:1

2. Abdel-wahab M, El-Husseiny T, El-Hanafy E, El Shobary M, Hamdy E (2010) Prognostic factors affecting survival and recurrence after hepatic resection for hepatocellular carcinoma in cirrhotic liver. Langenbeck's Arch Surg 395: 625-632

3. Chaiteerakij R, Addissie BD, Roberts LR (2015) Update on biomarkers of hepatocellular carcinoma. Clin Gastroenterol Hepatol 13(2):237-245

4. Noda K, Miyoshi E, Kitada T, Nakahara S, Gao CX, Honke K, Shiratori Y, Moriwaki H, Sasaki Y, Kasahara A, Hori M, Hayashi N, Taniguchi N (2002) The enzymatic basis for the conversion of nonfucosylated to fucosylated alphafetoprotein by acyclic retinoid treatment in human hepatoma cells: activation of alpha 1-6 fucosyltransferase. Tumor Biol 23:202-211

5. Li D, Mallory T, Satomura S (2001) AFP-L3: a new generation of tumor marker for hepatocellular carcinoma. Clin Chim Acta 313(1-2):15-19

6. Leerapun A, Suravarapu S, Bida JP, Clark RJ, Sanders EL, Mettler TE, Stadheim LM, Adreca I et al (2007) The utility of serum AFP-L3 in the diagnosis of hepatocellular carcinoma: evaluation in a U.S. referral population. Clin Gastroenterol Hepatol 5(3):394-402

7. Hu B, Tian X, Sun J, Meng X (2013) Evaluation of individual and combined applications of serum biomarkers for diagnosis of hepatocellular carcinoma: a meta-analysis. Int J Mol Sci 14:23559-23580

8. Mukai M, Endo $H$, Iwasaki T, Tatsuta M, Togawa A, Nakamura $H$, Inoue $M$ (2006) RhoC is essential for TGF-b1-induced invasive capacity of rat ascites hepatoma cells. Biochem Biophys Res Commun 346:74-82

9. Giannelli G, Villa E, Lahn M (2014) Transforming growth factor- $\beta$ as a therapeutic target in hepatocellular carcinoma. Cancer Res 74(7):1890-1894

10. Bruix J, Sherman M (2011) Management of hepatocellular carcinoma: an update. Hepatology 53:1020-1022

11. Llovet JM, Fuster J, Bruix J (2004) Barcelona-Clinic Liver Cancer Group. The Barcelona approach: diagnosis, staging, and treatment of hepatocellular carcinoma. Liver Transpl;10: S115-S120

12. Lencioni R, Llovet JM (2010) Modified RECIST (mRECIST) assessment for hepatocellular carcinoma. Semin Liver Dis 30(1):52-60

13. Crocetti L, de Baere T, Lencioni R (2010) Quality improvement guidelines for radiofrequency ablation of liver tumors. Cardiovasc Intervent Radiol 33(1):11-17

14. Holah NS, El-Azab DS, Aiad HA, Sweed DM (2015) Hepatocellular carcinoma in Egypt: epidemiological and histopathological properties. Menoufia Med J 28(3):718-724

15. El-Zayadi AR, Badran HM, Barakat EM, Attia MA, Shawky S, Mohamed MK, Selim O, Saeid A (2005) Hepatocellular carcinoma in Egypt: a single center study over a decade. World J Gastroenterol 11(33):5193-5198

16. Ke S, Ding XM, Qian X, Zhou YM, Cao BX, Gao K, Sun WB (2013) Radiofrequency ablation of hepatocellular carcinoma sized $>3$ and $\leq 5 \mathrm{~cm}$ : is ablative margin of more than $1 \mathrm{~cm}$ justified? World J Gastroenterol 19(42): 7389-7398

17. Wang W, Cheng J, Qin JJ, Voruganti S, Nag S, Fan J, Gao Q, Zhang R (2014) $R$ RYBP expression is associated with better survival of patients with hepatocellular carcinoma (HCC) and responsiveness to chemotherapy of HCC cells in vitro and in vivo. Oncotarget 5(22):11604-11619

18. Toshimori J, Nouso K, Nakamura S, Wada N, Morimoto Y, Takeuchi Y, Yasunaka T, Kuwaki K et al (2015) Local recurrence and complications after percutaneous radiofrequency ablation of hepatocellular carcinoma: a retrospective cohort study focused on tumor location. Acta Med Okayama 69(4):219-226

19. Kikuchi L, Menezes M, Chagas AL, Tani CM, Alencar RS, Diniz MA, Alves VA, D'Albuquerque LA et al (2014) Percutaneous radiofrequency ablation for 
early hepatocellular carcinoma: risk factors for survival. World J Gastroenterol 20(6):1585-1593

20. Lam VW, Ng KK, Chok KS, Cheung TT, Yuen J, Tung H, Tso WK, Fan ST et al (2008) Risk factors and prognostic factors of local recurrence after radiofrequency ablation of hepatocellular carcinoma. J Am Coll Surg 207(1):20-29

21. Zhang CZ, Liu L, Cai M, Pan Y, Fu J, Cao Y, Yun J (2012) Low SIRT3 expression correlates with poor differentiation and unfavorable prognosis in primary hepatocellular carcinoma. PLoS One 7(12):e51703

22. Yamashita F, Tanaka M, Satomura S, Tanikawa K (1995) Monitoring of lectinreactive alpha-fetoproteins in patients with hepatocellular carcinoma treated using transcatheter arterial embolization. Eur J Gastroenterol Hepatol 7:627-633

23. Okuda K, Tanaka M, Kanazawa N, Nagashima J, Satomura S, Kinoshita H, Eriguchi N, Aoyagi S et al (1999) Evaluation of curability and prediction of prognosis after surgical treatment for hepatocellular carcinoma by lens culinaris agglutinin-reactive alpha-fetoprotein. Int J Oncol 14:265-271

24. Hayashi K, Kumada T, Nakano S, Takeda I, Sugiyama K, Kiriyama S, Sone Y, Miyata A et al (1999) Usefulness of measurement of Lens culinaris agglutinin-reactive fraction of alpha-fetoprotein as a marker of prognosis and recurrence of small hepatocellular carcinoma. Am J Gastroenterol 94(10):3028-3033

25. Tsai JF, Jeng JE, Chuang LY, Yang ML, Ho MS, Chang WY, Hsieh MY, Lin ZY et al (1997) Elevated urinary transforming growth factor-beta1 level as a tumor marker and predictor of poor survival in cirrhotic hepatocellular carcinoma. Br J Cancer 76(2):244-250

26. Ji F, Fu SJ, Shen SL, Zhang $\sqcup$, Cao QH, Li SQ, Peng BG, Liang $\sqcup$ et al (2015) The prognostic value of combined TGF- $\beta 1$ and ELF in hepatocellular carcinoma. BMC Cancer 15:116

27. Kohla MA, Attia A, Darwesh N, Obada M, Taha H, Youssef MF (2017) Association of serum levels of transforming growth factor $\beta 1$ with disease severity in patients with hepatocellular carcinoma. $\backslash ; 3: 294-301$

28. Toro A, Ardiri A, Mannino M, Arcerito MC, Mannino G, Palermo F, Bertino G, Di Carlo I (2014) Effect of pre- and post-treatment a-fetoprotein levels and tumor size on survival of patients with hepatocellular carcinoma treated by resection, trans-arterial chemoembolization or radiofrequency ablation: a retrospective study. BMC Surg 14:40

29. Corey KE, Pratts DS (2009) Current status of therapy for hepatocellular carcinoma. Ther Adv Gastroenterol 2:45-57

30. Wang NY, Wang C, Li W, Wang GJ, Cui GZ, He H, Zhao HJ (2014) Prognostic value of serum AFP, AFP-L3, and GP73 in monitoring short-term treatment response and recurrence of hepatocellular carcinoma after radiofrequency ablation. Asian Pac J Cancer Prev 15:1539-1545

31. Cheng J, Wang W, Zhang Y, Liu X, Li M, Wu Z, Liu Z, Lv Y et al (2014) Prognostic role of pre-treatment serum AFP-L3\% in hepatocellular carcinoma: systematic review and meta-analysis. PLoS One 9(1):87011

\section{Publisher's Note}

Springer Nature remains neutral with regard to jurisdictional claims in published maps and institutional affiliations.

\section{Submit your manuscript to a SpringerOpen ${ }^{\circ}$ journal and benefit from:}

- Convenient online submission

- Rigorous peer review

- Open access: articles freely available online

- High visibility within the field

- Retaining the copyright to your article

Submit your next manuscript at $\boldsymbol{\nabla}$ springeropen.com 